International Journal of Current Advanced Research

ISSN: O: 2319-6475, ISSN: P: 2319 - 6505, Impact Factor: SJIF: 5.995

Available Online at www.journalijcar.org

Volume 6; Issue 4; April 2017; Page No. 3493-3496

DOI: http://dx.doi.org/10.24327/ijcar.2017.3496.0301

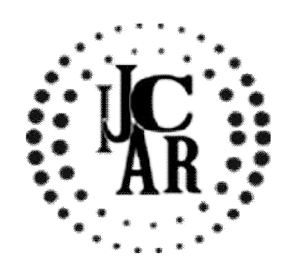

Research Article

\title{
EXPERIENCE OF OMOM CAPSULE 2 ENDOSCOPY SYSTEM FOR SUSPECTED SMALL BOWEL PATHOLOGY IN A TROPICAL COUNTRY
}

\section{Tarun J George., Prem Kumar K., Kani Shaikh Mohamed., A Murali., T Pughazhendhi and Kini Ratnakar}

Institute of Medical Gastroenterology Madras Medical College

\begin{tabular}{l}
\hline A R T I C L E I N F O \\
Article History: \\
Received $25^{\text {th }}$ January, 2017 \\
Received in revised form $10^{\text {th }}$ February, 2017 \\
Accepted $14^{\text {th }}$ March, 2017 \\
Published online $28^{\text {th }}$ April, 2017
\end{tabular}

Key words:

Endoscopy system, Small bowel

\begin{abstract}
A B S T R A C T
Background: Capsule endoscopy (CE) is a useful tool in evaluating small bowel pathologies. The experience regarding the diagnostic efficiency of OMOM capsule 2 (Jinshan Science and Technology Company, Chongqing, China) in tropical countries are limited. There is controversy regarding the use of capsule endoscopy in resource poor tropical countries.

Methods: This was a prospective observational study conducted during a 24-month period from January 2015 to December 2016. The aim was to evaluate the diagnostic efficiency of OMOM capsule 2 (Jinshan Science and Technology Company, Chongqing, China) for various indications such as obscure GI bleed (OGIB), chronic diarrhea, and abdominal pain. A total of nineteen patients were included among which nine were for obscure GI bleed, one case of unexplained abdominal pain and remaining nine patients were for chronic diarrhea.

Results: Abnormal findings were noted in six out of the nine patients $(66.7 \%)$ with OGIB and chronic diarrhea respectively. Findings in patients presenting with OGIB included two cases of angioectasia, two cases of hookworm infestation, one case of small bowel ulcers and one case with two lesions which were angioectasia with jejunal ulcer. The remaining three cases had a normal study. CE findings in patients with chronic diarrhea were two cases of intestinal lymphangiectasia, one case with features suggestive of intestinal villous atrophy with scalloped valvulaeconniventes and later diagnosed as tropical sprue, one case of celiac disease with persistent symptoms despite gluten free diet on CE had ulcerojejunitis. Crohns disease and strongyloidiasis were the other two cases diagnosed on CE. The remaining three patients out of the nine with chronic diarrhea had a normal study. Only one patient was evaluated with CE for unexplained abdominal pain and was found to have nodular lesions in duodenum confirmed on histopathology as Brunner's gland hyperplasia with SOL in ileum probably due to extraneous impression. Further evaluation could not be done as patient refused further treatment. There were no complications noted in any of the nineteen patients

Conclusion: The OMOM capsule 2 endoscopy system is safe and has similar diagnostic efficacy as the other capsule endoscopic systems currently in use among patients presenting with obscure GI bleed and chronic diarrhea.
\end{abstract}

Copyright $₫ 2017$ Tarun J George et al. This is an open access article distributed under the Creative Commons Attribution License, which permits unrestricted use, distribution, and reproduction in any medium, provided the original work is properly cited.

\section{INTRODUCTION}

Capsule endoscopy is a useful tool in the evaluation of patients with gastrointestinal bleed especially when EGD and colonoscopy are unremarkable. The other indications of CE are suspected Crohn's disease, polyposis syndromes such as familial adenomatous polyposis syndrome, Peutz-Jeghers syndrome, chronic unexplained abdominal pain and chronic diarrhea. ${ }^{1}$ Push enteroscopy allows visualization up-to proximal jejunum.

\footnotetext{
*Corresponding author: Tarun J George Institute of Medical Gastroenterology Madras Medical College
}

This limitation was overcome by Double balloon and single balloon enteroscopy whereby the entire small bowel can be visualized by an antegrade or combination of antegrade and retrograde approach. Balloon enteroscopy is generally preferred in suspected small bowel obstruction where by balloon dilatation can be done for strictures, resection of polyps, retrieval of foreign bodies, and in few instances placement of metallic stents. ${ }^{2}$ The advantages of CE are that it can be done in outpatient basis, allows visualization of the entire small bowel with no requirement for sedation as it is non-invasive. However, its use is limited by the cost, inability to take samples for histopathology and carry out endoscopic therapy. We wanted to assess the diagnostic efficiency and 
share our experience of OMOM capsule 2 (Jinshan Science and Technology Company, Chongqing, China) for various indications such as obscure GI bleed (OGIB), chronic diarrhea, and abdominal pain.

\section{MATERIALS AND METHODS}

Consecutive patients with suspected small intestinal pathology seen at Institute of Medical Gastroenterology, Madras Medical College, India from January $1^{\text {st }} 2015$ up-to December $31^{\text {st }} 2016$ were recruited. Indications were obscure GI bleed, suspected Crohn's disease, chronic diarrhea, and chronic unexplained abdominal pain. Pregnant subjects, and patients with small bowel obstruction, swallowing disorders, cardiac pacemakers were excluded from the study. The study was approved by the Hospital Ethics Committee. Informed consent was taken prior to the procedure.

Capsule endoscopy was carried out using of OMOM capsule 2 (Jinshan Science and Technology Company, Chongqing, China). The dimensions are $25.4 \mathrm{~mm} \times 11 \mathrm{~mm}$ and weighs 4.5 grams. The battery life is approximately 10 hours which takes $>50,000$ images in total. The images were transmitted by a radiofrequency transmitter and captured by the antenna system which is integrated into the belt which is connected to a recorder that stores the images.

Capsule endoscopy was carried out after bowel preparation with polyethylene glycol and 12 hour overnight fasting. The recorder assembly which consists of the sensor belt along with the recorder were worn over the abdomen at the umbilical level. Half an hour prior to the procedure $600 \mathrm{mg}$ of simethicone solution was given. Patients swallowed the OMOM capsule with a glass of water. The patients were allowed to take clear colorless liquids 4 hours after swallowing the capsule and were kept in hospital for the complete duration of the procedure. The recording was continued until the CE battery ran out of charge after which the assembly was switched off and the data was downloaded to a computer workstation using proprietary software of the OMOM capsule endoscopy system. Using this software, the images were analyzed and read by a single investigator and reviewed by two senior gastroenterologist with extensive experience in capsule endoscopy. Patients were reviewed after 1 week to assess for any complications such as capsule retention, and if patients didn't notice to have passed the capsule in stool an abdominal $x$ ray was done.

\section{Statistics Analysis}

Quantitative variables were expressed as mean $\pm S D$ values, qualitative variables as percentages.

\section{RESULTS}

Capsule endoscopy was done in nineteen patients among which 12 were male and 7 were female patients. The mean age of the patients was 41.42 (Standard Deviation: 18.225). In four patients, the complete screening of small bowel could not be done as the capsule battery exhausted even before the capsule could pass the ileo-cecal valve because of the increased gastric transit times. The average gastric transit time among the nineteen patients were 81.63 minutes (Standard deviation 89.86) and small bowel transit time among the fifteen patients were 296.20 minutes (Standard Deviation: 126.76). Among the nineteen patients, nine were evaluated for obscure GI, nine for chronic diarrhea and remaining one for chronic unexplained abdominal pain. In the obscure GI bleed group, $55.6 \%$ presented as occult and $44.4 \%$ presented as overt GI bleed. Diagnostic yield of CE in obscure GI bleed and chronic diarrhea were 6/9 (66.7\%) and abnormal findings were also noted in the patient with unexplained abdominal pain. Abnormal findings noted in $\mathrm{CE}$ in patients who presented with obscure GI bleed were two cases of small bowel parasitosis, angioectasia in three patients, and isolated jejunal ulcers in one patient. Among the three patients with angioectasia, two patients had an additional finding of ulcers in the jejunum and polypoidal lesion in the jejunum respectively. The remaining three of the nine patients who presented with obscure GI bleed had normal findings. CE findings in the nine patients evaluated for chronic diarrhea were two patients had intestinal lymphangiectasia, one case of features suggestive of Crohns disease confirmed histopathologically and one case of parasitic larvae noted in the ileal fluid which later turned out to be strongyloidiasis on histo-pathology of duodenal biopsy. Two patients had features suggestive of celiac disease among which one was later diagnosed as tropical sprue and the other was diagnosed as celiac disease with additional findings of ulcero-jejunitis. Findings in the patient with unexplained abdominal pain showed nodular lesions in distal duodenum which was also noted on EGD and submucosal bulge in the ileum probably due to an extrinsic compression. Histopathology of the nodules in duodenum turned out to be Brunners gland hyperplasia and the findings of suspected submucosal bulge in the ileum could not be confirmed with further imaging or surgery as the patient refused for further evaluation.

There were no adverse events in any of the nineteen patients and all patients had passed out the capsule. All the patients found the capsule easy to swallow, painless and preferred it from conventional endoscopy

Figure 1 Type of lesions in small bowel detected on CE

\begin{tabular}{cc}
\hline Findings & Number \\
\hline Total & 19 \\
Hookworm infestation & $2(10.5 \%)$ \\
Ulcers & $4(21.1 \%)$ \\
Angioectasia & $3(15.8 \%)$ \\
Polyps & $1(5.3 \%)$ \\
Villous atrophy & $3(15.8 \%)$ \\
Erosions & $1(5.3 \%)$ \\
Lymphangiectasia & $2(10.5 \%)$ \\
Parasitic larvae ( Strongyloidiasis ) & $1(5.3 \%)$ \\
Stricture & $1(5.3 \%)$ \\
Nodular lesion duodenum & $1(5.3 \%)$ \\
\hline
\end{tabular}

Table 2 Comparison of lesions between OGIB, chronic diarrhea and abdominal pain

\begin{tabular}{|c|c|c|c|}
\hline \multicolumn{4}{|c|}{ Number } \\
\hline Findings & OGIB & $\begin{array}{l}\text { Chronic } \\
\text { diarrhea }\end{array}$ & $\begin{array}{l}\text { Abdominal } \\
\text { Pain }\end{array}$ \\
\hline Total positive cases & $6 / 9(66.7 \%)$ & $6 / 9(66.7 \%)$ & 1 \\
\hline Angioectasia & $3(33.3 \%)$ & 0 & 0 \\
\hline Lymphangiectasia & 0 & $2(22.2 \%)$ & 0 \\
\hline Crohns disease & 0 & $1(11.1 \%)$ & 0 \\
\hline Celiac disease & 0 & $1(10 \%)$ & 0 \\
\hline Tropical Sprue & 0 & $1(10 \%)$ & 0 \\
\hline $\begin{array}{l}\text { Hookworm } \\
\text { infestation }\end{array}$ & $2(22.2 \%)$ & 0 & 0 \\
\hline Ulcers & $2(22.2 \%)$ & $2(22.2 \%)$ & 0 \\
\hline Strongyloidiasis & 0 & $1(11.1 \%)$ & 0 \\
\hline Polyp & $1(11.1 \%)$ & 0 & 0 \\
\hline Erosions & 0 & $1(11.1 \%)$ & 0 \\
\hline Nodular lesion & 0 & 0 & 1 \\
\hline
\end{tabular}




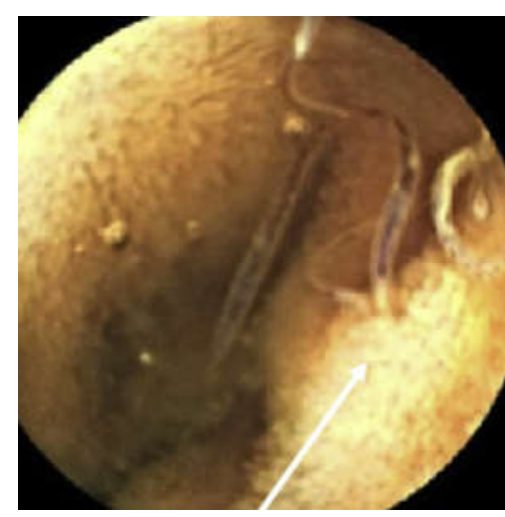

Image $1 \mathrm{Small}$ bowel parasitosis in distal duodenum in a patient presenting with Obscure GI bleed

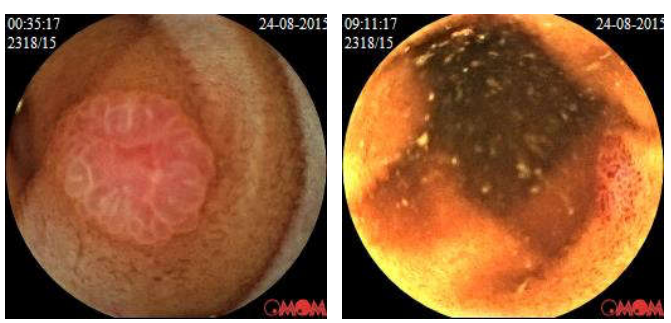

Image 2 Jejunal Polyp with angioectasia in jejunum in a chronic liver disease patient presenting with overt small bowel bleed suggestive of portal hypertensive enteropathy

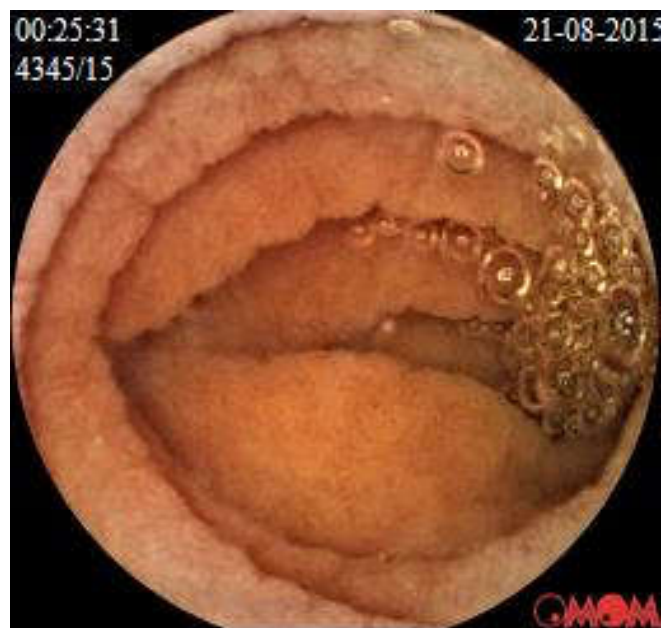

Image 3 Duodenal mucosal fold scalloping in a patient with tropical sprue

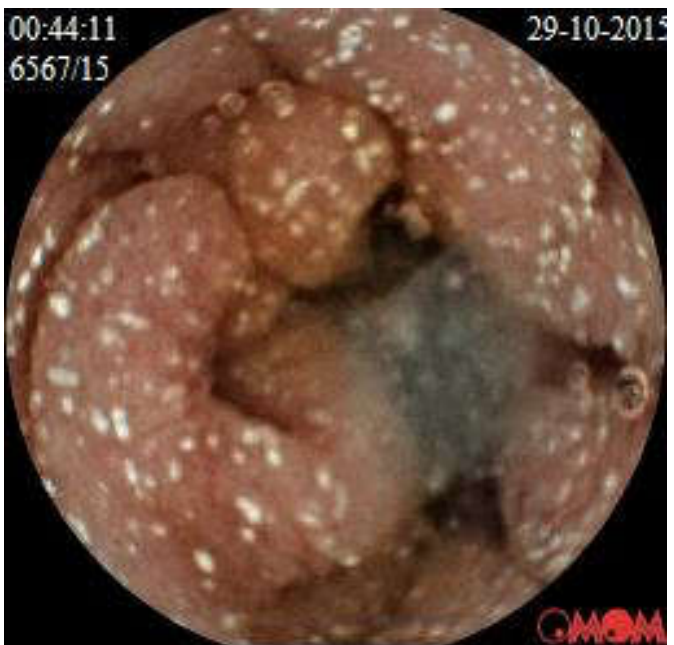

Image 4 Whitish spots in jejunal mucosa s/o Intestinal lymphangiectasia in a patient presenting with protein losing enteropathy

\section{DISCUSSION}

Capsule endoscopy has gained widespread acceptance in the evaluation of patients with suspected small bowel pathology especially in the diagnostic algorithm of OGIB. Before the advent of $\mathrm{CE}$, various other diagnostic modalities wereused such as push enteroscopy, barium studies and angiography. Double balloon enteroscopy (DBE) has been used in many centers for evaluating OGIB. However, CE has been to found to have a significantly higher yield compared to DBE examination done via the oral or anal route in the setting of OGIB. $^{3}$

The detection rate for source of bleed for CE among patients with obscure GI in our study is similar to already published literature. ${ }^{4-7}$ In our study angioectasia was the commonest etiology in patients presenting withOGIB.Hookworm infestation was diagnosed in two out the nine patients with OGIB which is an interest finding that is not being reported in similar studies in western population. Among the two patients with hookworm infestation, one presented with overt GI bleed in the form of melena with severe anemia which required multiple packed red blood cell transfusion and the other presented with occult GI bleed with iron deficiency anemia. Both patients responded to anti-helminthic and iron supplementation. Ghoshal et al evaluated CE in obscure GI bleed in 86 patients and found hookworm infestation in $7.8 \%{ }^{5}$ The diagnostic yield of CE endoscopy depends on the optimum timing which is ideally within the 48 hours of the bleed but can be extended up to a maximum of 2 weeks and the presence of overt or occult GI bleed where the diagnostic yield were much higher ( $87 \%$ vs $46 \%$ ) in patients presenting with overt GI bleed .

The remaining cases in our study with regard to obscure GI bleed had more than one lesion noted such as a combination of angioectasia with small bowel ulcers or polyp. Only one case had isolated jejunal ulcer of unknown etiology. The commonest lesions detected in Indian studies on CE for obscure GI bleed were small bowel ulcers and erosions. ${ }^{4}$ In our study among the nine patients with chronic diarrhea the commonest findings noted on $\mathrm{CE}$ were intestinal lymphangiectasia, followed by celiac disease, Crohns disease, strongy loidiasis. One case had features suggestive of celiac disease but serology was negative and was empirically treated for tropical sprue after which the patient had improved. The commonest etiology in patients with chronic diarrhea in Egyptian population diagnosed by CE were celiac disease and crohns disease. ${ }^{8}$ The findings of larvae of Strongyloidesstercoralis seen in the ileal fluid captured on capsule endoscopy is uncommon which was later confirmed in our patient on histopathology as well. ${ }^{9} \mathrm{CE}$ could be an alternate method of diagnosing strongly oidesstercoralis infection in patients with chronic diarrhea and malabsorption in endemic areas where the suspicion is high in settings where the stool examination as well as histopathology are in conclusive. However, Strongyloidesstercoralis larvae must be differentiated from the 2 species of hookworms i.e. Ancylostomaduodenale and Necatoramericanus.

Various studies have shown that there isvery limited role for $\mathrm{CE}$ in the setting of chronic unexplained abdominal pain. ${ }^{10}$ Our study evaluated CE findings in only one patient which had abnormal findings of nodular lesions in duodenum which was later confirmed as Brunner's gland hyperplasia and 
suspected submucosal bulge in the terminal ileum which could not be further evaluated. Due to the lack of sufficient cases, the role of $\mathrm{CE}$ in our study for the evaluation chronic unexplained abdominal pain could not be established the main drawback of our study was that the abnormalities detected on $\mathrm{CE}$ could not be confirmed due to the lack of double/single balloon enteroscopy in our center. Secondly this study does not provide long term follow-up of patients and hence it is difficult to draw a conclusion as to the fate of the patients who had normal findings on capsule endoscopy.

However, in our relatively small series we have found $\mathrm{CE}$ a helpful endoscopic technique in diagnosing OGIB and a useful adjunct in the evaluation of chronic diarrhea when other primary diagnostic modalities are not contributory. $\mathrm{CE}$ assists in picking up and localizing the lesions in the small bowel to provide a road map for more invasive endoscopic techniques such as DBE for biopsy or endo-therapy, similar to how MRCP provides a roadmap for therapeutic ERCP.

\section{CONCLUSION}

The OMOM capsule 2 endoscopy system is safe to use and has similar diagnostic efficacy as the other capsule endoscopic systems currently in useamong patients presenting with obscure GI bleed and chronic diarrhea.

\section{References}

1. Katsinelos $\mathrm{P}$, Tziomalos $\mathrm{K}$, Fasoulas $\mathrm{K}$, et al. Can capsule endoscopy be used as a diagnostic tool in the evaluation of nonbleeding indications in daily Clinical practice? A prospective study. Med Princ Pract 2011;20(4):362-7.

2. May A. Balloon Enteroscopy: Single- and DoubleBalloon Enteroscopy. Gastrointest Endosc Clin N Am [Internet] 2009;19(3):349-56. Available from: http://dx.doi.org/10.1016/j.giec.2009.04.003
3. Chen X, Ran ZH, Tong JL. A meta-analysis of the yield of capsule endoscopy compared to doubleballoon enteroscopy in patients with small bowel diseases. World J Gastroenterol 2007;13(32):4372-8.

4. Goenka MMK, Majumder S, Kumar S, Sethy PPK, Goenka U. Single center experience of capsule endoscopy in patients with obscure gastrointestinal bleeding. World $J$ Gastroenterol [Internet] 2011;17(6):774-8. Available from: http:// www. pubmedcentral.nih.gov/articlerender.fcgi?artid $=304265$ $6 \&$ tool $=$ pmcentrez\&rendertype $=$ abstract

5. Ghoshal UC, Lakshmi CP, Kumar S, et al. Capsule endoscopy for obscure gastrointestinal bleeding in the tropics: Report from India. Dig Endosc 2011;23(1):1723.

6. Ang T-L, Fock K-M, Ng T-M, Teo E-K, Tan Y-L. Clincial utility, safety and tolerability of capsule endoscopy in urban Southeast Asian Population. World J Gastroenterol 2003;9(10):2313-1316.

7. Calabrese $\mathrm{C}$, Liguori $\mathrm{G}$, Gionchetti $\mathrm{P}$, et al. Obscure gastrointestinal bleeding: Single centre experience of capsule endoscopy. Intern Emerg Med 2013;8(8):6817.

8. Zakaria MS, Abdelrahim AY, Abdelbary MS, Zakaria KS, Mahmoud SH, Abied MA. Video Capsule Endoscopy in Egyptian Patients with Chronic Diarrhea. 2013;8(2):165-9.

9. Xouris D, Vafiadis-Zoumbulis I, Papaxoinis K, et al. Possible Strongyloides stercoralis infection diagnosed by videocapsule endoscopy in an immunocompetent patient with devastating diarrhea. Ann Gastroenterol 2012;25(3):268-70.

10. Ersoy O, Sivri B, Arsian S, Batman F, Bayraktar Y. How much helpful is the capsule endoscopy for the diagnosis of small bowel lesions? World $J$ Gastroenterol 2006;12(24):3906-10.

\section{How to cite this article:}

Tarun J George et al (2017) ' Experience Of Omom Capsule 2 Endoscopy System For Suspected Small Bowel Pathology In A Tropical Country', International Journal of Current Advanced Research, 06(04), pp. 3493-3496.

DOI: http://dx.doi.org/10.24327/ijcar.2017.3496.0301 